\title{
Pulmonary emphysema induced by passive smoking: an experimental study in rats
}

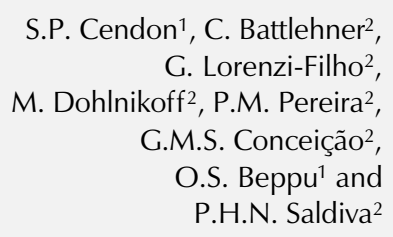

\author{
${ }^{1}$ Disciplina de Pneumologia, Escola Paulista de Medicina, \\ Universidade Federal de São Paulo, São Paulo, SP, Brasil \\ ${ }^{2}$ Laboratório de Poluição Atmosférica Experimental, Instituto do Coração, \\ Faculdade de Medicina, Universidade de São Paulo, São Paulo, SP, Brasil
}

\section{Correspondence \\ P.H.N. Saldiva \\ Laboratório de Poluição \\ Atmosférica Experimental \\ Faculdade de Medicina, USP \\ Av. Dr. Arnaldo, 455 \\ 01246-903 São Paulo, SP \\ Brasil}

Research supported by CNPq, FAPESP, EPM and LIM-HCFMUSP.

Received January 13, 1997 Accepted August 5, 1997

\begin{abstract}
We describe a short time model for inducing experimental emphysema in rats by chronic tobacco smoke inhalation. Three groups of male Wistar rats (6 months old) were studied: controls $(\mathrm{N}=8)$, rats intoxicated for 45 days ( $(-45, N=7)$ or for 90 days $(s-90, N=8)$. The exposed animals were intoxicated 3 times a day (10 cigarettes per exposure period), 5 days a week. Pulmonary damage was assessed by means of functional tests and quantitative pathological examination of the airways and lung parenchyma. The s- 45 and s- 90 animals were similar in terms of functional residual capacity (FRC) corrected for body weight $(\mathrm{FRC} / \mathrm{kg})$ but both groups of smoking rats exhibited significantly higher $\mathrm{FRC} / \mathrm{kg}$ values than the controls ( $\mathrm{s}-45=6.33$; $\mathrm{s}-90$ $=6.46 ;$ controls $=3.78 ; \mathrm{P}<0.05$ ). When the two groups of smoking rats were pooled together and compared to controls, they showed decreased lung elastance (1.6 vs 2.19; $\mathrm{P}=0.046)$ and increased mean linear intercept $(\mathrm{Lm})(85.14$ vs $66.44 ; \mathrm{P}=0.025)$. The s-90 animals presented higher inflammation and muscular hypertrophy at the level of the axial bronchus than the controls $(\mathrm{P}<0.05)$. When smoking groups were pooled and compared to controls, they presented significantly higher inflammation at the lateral level $(\mathrm{P}=0.028)$, as well as airway secretory hyperplasia $(\mathrm{P}=0.024)$ and smooth muscle hypertrophy $(\mathrm{P}=0.005)$ at the axial level. Due to its simplicity, low cost and short duration, this technique may be a useful model to obtain new information about airspace remodeling due to chronic tobacco consumption.
\end{abstract}

\section{Introduction}

Although tobacco smoke is responsible for pulmonary emphysema in humans, the literature on animal models of tobacco-induced emphysema is limited. Experimental tobacco inhalation protocols in animals usually describe a histopathological picture domi-
Key words

- Passive smoking

- Emphysema

- Rats

- Pulmonary function

- Morphological analysis

- Quantification nated by airway inflammation rather than a consistent enlargement of distal airspaces (1-3).

In a rat model, Huber et al. (4) demonstrated an enlargement of distal airspaces and a decrease in alveolar surface after prolonged exposure to tobacco smoke (6 months). In view of the difficulties of carry- 
ing out such a prolonged exposure, shortterm experimental models could facilitate the development of protocols for the study of the effects of tobacco products on distal pulmonary parenchyma.

Recently, Wright and Churg (5) reported that guinea pigs developed significant morphological and functional emphysematous cigarettes a day. The objective of the present study was to develop a method to reduce the time needed to induce morphological and functional emphysema in rats by increasing the dose of tobacco inhalation.

\section{Material and Methods}

\section{Inhalation system}

Our inhalation system device was based

Figure 1 - Illustration of the inhalation system. alterations after 90 days of exposure to 10

on the work of Le Mesurier et al. (6). The inhalation chamber consisted of a hermetically closed acrylic box ( $30 \times 25 \times 15 \mathrm{~cm})$ divided into two equal parts. In one compartment, 10 commercially available cigarettes were placed to burn simultaneously. This part of the chamber was ventilated with a flow rate of compressed air set at $10 \mathrm{l} / \mathrm{min}$. Under these conditions, the cigarettes burned for approximately $10 \mathrm{~min}$. The other half of the acrylic box was the place in which the rats were exposed (whole body) to the cigarette smoke by receiving the output of the burning compartment (Figure 1). In essence, the rats received a whole-body exposure to "side stream" smoke, which was able to promote a significant increase in the levels of carboxyhemoglobin $(\mathrm{COHb})$ (Table 1).

\section{Exposure protocol}

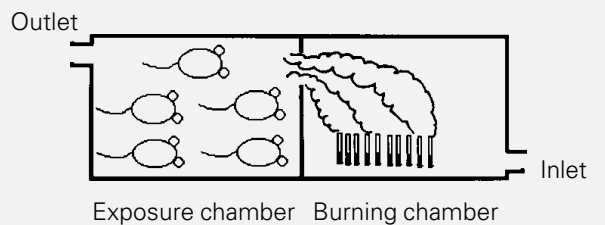

Table 1 - Carboxyhemoglobin $(\mathrm{COHb})$, body weights (BW) (before and after the experiments), and food and water consumption of rats during the study (controls; exposure to cigarette smoke for 45 days (s-45) or 90 days (s-90)).

*Statistically significant difference among the groups, with the values of $\mathrm{COHb}$ of the control group being smaller than those of smoking rats $(P<0.05$, ANOVA); * significant differences among the groups with respect to body weight before exposure $(P<0.05$, ANOVA); ***significant differences of time $x$ smoking interaction in terms of body weight. Control animals increased their body weights, whereas smoking rats did not $(\mathrm{P}<0.05$, ANOVA).

\begin{tabular}{lccccc}
\hline Group & $\begin{array}{c}{ }^{*} \mathrm{COHb} \\
(\%)\end{array}$ & $\begin{array}{c}*{ }^{*} \mathrm{BW} \text { before } \\
(\mathrm{g})\end{array}$ & $\begin{array}{c}* *{ }^{*} \mathrm{BW} \text { after } \\
(\mathrm{g})\end{array}$ & $\begin{array}{c}\text { Food } \\
(\mathrm{g} / \mathrm{kg})\end{array}$ & $\begin{array}{c}\text { Water } \\
(\mathrm{ml} / \mathrm{kg})\end{array}$ \\
\hline Control (N = 8) & & & & & \\
$\quad$ Mean & 2.26 & 306.6 & 332.0 & 69.54 & 129.08 \\
$\quad$ Standard deviation & 1.30 & 30.5 & 29.0 & 6.5 & 10.8 \\
s-45 (N = 7) & & & & & \\
$\quad$ Mean & 4.46 & 340.6 & 339.7 & 65.61 & 119.05 \\
$\quad$ Standard deviation & 1.3 & 15.8 & 12.9 & 10.9 & 20.4 \\
s-90 (N = 8) & & & & & \\
$\quad$ Mean & 4.01 & 388.1 & 354.6 & 59.31 & 109.5 \\
$\quad$ Standard deviation & 2.4 & 20.8 & 13.3 & 2.3 & 0.87
\end{tabular}

Twenty-three adult male Wistar rats aged 6 months at the beginning of the experiment were studied. The animals received a balanced diet and water ad libitum throughout the study. The experimental groups were divided as follows: 45 days of exposure (s-45), $\mathrm{N}=7 ; 90$ days of exposure (s-90), $\mathrm{N}=8$, and exposure to compressed air (controls), $\mathrm{N}=8$.

Four control animals were examined after 45 days of exposure to compressed air, whereas the four remaining control rats were studied after 90 days of exposure to the same clean atmosphere. The animals were challenged 3 times a day ( 10 cigarettes per exposure period), 5 days a week.

Body weight (before and after the experiment), and mean daily food and water consumption are reported in Table 1.

\section{Pulmonary function measurements}

Pulmonary measurements were made on anesthetized animals ( $30 \mathrm{mg} / \mathrm{kg}$ sodium pentobarbital, ip) intubated with a snugly fitting tracheal cannula (2 mm ID) during sponta- 
neous respiratory movements (7). A pneumotachograph was connected to the tracheal cannula for the measurement of airflow (V) and, by electronic integration, of changes in lung volume (V) (8). A water-filled polyethylene catheter was introduced into the esophagus to estimate pleural pressure (Ppl) (7). Transpulmonary pressure $\left(\mathrm{P}_{\mathrm{L}}\right)$ was measured by subtracting Ppl from airway opening pressure. The proper positioning of the esophageal catheter in rats has been previously described (7). $\dot{V}, V$ and $P_{L}$ were recorded with a pen chart recorder. $\mathrm{V}$ and $\mathrm{P}_{\mathrm{L}}$ were sampled at a frequency of $200 \mathrm{~Hz}$ with a 12 bit analog-to-digital converter (DT 2801A, Data Translation, Marlboro, MA), and stored on a computer for off-line analysis. For each rat, 14 to 15 breath cycles were averaged before computing resistance $\left(\mathrm{R}_{\mathrm{L}}\right)$ and elastance $\left(\mathrm{E}_{\mathrm{L}}\right)$ by the least squares procedure according to the equation:

$$
\mathrm{P}_{\mathrm{L}}(\mathrm{t})=\mathrm{E}_{\mathrm{L}} \cdot \mathrm{V}(\mathrm{t})+\mathrm{R}_{\mathrm{L}} \cdot \dot{\mathrm{V}}(\mathrm{t})+\text { Error }
$$

In addition to $\mathrm{R}_{\mathrm{L}}$ and $\mathrm{E}_{\mathrm{L}}$, tidal volume $\left(\mathrm{V}_{\mathrm{T}}\right)$, inspiratory time $\left(\mathrm{T}_{\mathrm{I}}\right)$, expiratory time $\left(\mathrm{T}_{\mathrm{E}}\right)$, and duration of the total respiratory cycle $\left(\mathrm{T}_{\mathrm{TOT}}\right)$ were determined based on the $\mathrm{V}$ signal. The duty cycle $\left(\mathrm{T}_{\mathrm{I}} / \mathrm{T}_{\mathrm{TOT}}\right)$ and the mean inspiratory flow $\left(\mathrm{V}_{\mathrm{T}} / \mathrm{T}_{\mathrm{I}}\right)$ were calculated from these data.

\section{Measurement of functional residual capacity}

After the evaluation of pulmonary function, the rats were sacrificed by sectioning the abdominal aorta. Before opening the chest, a 1-ml pipette with a soap meniscus was connected to the breathing circuit, as previously described (9). The volume change of the lung $(\Delta \mathrm{V}, \mathrm{ml})$ due to the opening of the chest wall was measured by determining the displacement of the soap meniscus. After this procedure, the trachea was tied, the heart and mediastinal structures were carefully dissected and the weight of the lung (LW, g) was measured. Lung volume ( $\mathrm{LV}, \mathrm{ml}$ ) was then determined by saline displacement.
Functional residual capacity (FRC) corrected for body weight $(\mathrm{FRC} / \mathrm{kg})$ was calculated by the equation:

$\mathrm{FRC} / \mathrm{kg}=(\Delta \mathrm{V}+\mathrm{LV}-\mathrm{LW}) / \mathrm{kg}$ body weight assuming that the density of lung parenchyma is 1 .

\section{Morphological studies}

After measuring FRC, the lungs were fixed for $48 \mathrm{~h}$ by intratracheal instillation of buffered formalin solution at a transpulmonary pressure of $25 \mathrm{cmH}_{2} \mathrm{O}$. Sagittal sections were taken from the left lung and processed by routine histological procedures for paraffin embedding. Five- $\mu$ m thick histological sections were stained with hematoxylin-eosin and the combination of Schiff's periodic acid and Alcian blue, $\mathrm{pH} 2.5$.

Pathological alterations of the airways were assessed both at the axial and lateral bronchus levels by means of a semi-quantitative pathological score. The degrees of inflammation, secretory hyperplasia, muscular hypertrophy, and fibrosis of the airway wall were scored from 0 (absent) to 3 (intense) by two pathologists who examined the slides at the same time under a doubleobservation microscope. The histological slides were coded and both pathologists were unaware of whether the slide under examination was from a smoking or a control animal.

Alveolar destruction was identified by the determination of the mean linear intercept (Lm) (10). For this purpose, 4 noncoincident, randomly selected, microscopic fields (100X) were examined with the aid of an integrating eyepiece provided with 50 lines of $100 \mu \mathrm{m}$ each.

\section{Statistical analysis}

In order to compare the group means of the parameters studied, except for the pathological scores, analysis of variance (ANOVA) 
was employed followed by the StudentNewman-Keuls multiple comparison test. The pathological scores were analyzed by the Kruskal-Wallis test and multiple comparison procedures. When comparing controls with the two groups of smoking rats (s$45+\mathrm{s}-90)$, the Student $t$-test and the MannWhitney test were employed. The level of significance was set at $5 \%$ in all cases.

Table 2 - Effect of passive smoking for 45 or 90 days on respiratory cycle-related parameters: tidal volume $\left(\mathrm{V}_{\mathrm{T}}\right)$; inspiratory $\left(\mathrm{T}_{1}\right)$ and total respiratory cycle $\left(\mathrm{T}_{\mathrm{TOT}}\right)$ times; duty cycle $\left(\mathrm{T}_{1} / \mathrm{T}_{\mathrm{TOT}}\right)$ and mean inspiratory flow $\left(\mathrm{V}_{\mathrm{T}} / \mathrm{T}_{1}\right)$.

The $P$ value for the comparison of the three groups by ANOVA is given in the last column.

\begin{tabular}{|c|c|c|c|c|c|}
\hline & \multicolumn{3}{|c|}{ Group } & \multirow{2}{*}{$\begin{array}{l}\text { Group } \\
\text { (total) }\end{array}$} & \multirow{2}{*}{$\begin{array}{l}\text { ANOVA } \\
\text { (P value) }\end{array}$} \\
\hline & $\begin{array}{l}\text { Control } \\
(N=8)\end{array}$ & $\begin{array}{c}s-45 \\
(N=7)\end{array}$ & $\begin{array}{c}s-90 \\
(N=8)\end{array}$ & & \\
\hline \multicolumn{6}{|l|}{$\mathrm{V}_{\mathrm{T}}(\mathrm{ml})$} \\
\hline Mean & 1.32 & 1.41 & 1.61 & 1.45 & 0.13 \\
\hline Median & 1.29 & 1.43 & 1.47 & 1.41 & \\
\hline Standard deviation & 0.18 & 0.23 & 0.39 & 0.30 & \\
\hline Minimum & 1.06 & 1.07 & 1.36 & 1.06 & \\
\hline Maximum & 1.59 & 1.71 & 2.52 & 2.52 & \\
\hline \multicolumn{6}{|l|}{$\mathrm{T}_{1}(\mathrm{~s})$} \\
\hline Mean & 0.35 & 0.32 & 0.31 & 0.33 & 0.70 \\
\hline Median & 0.33 & 0.28 & 0.30 & 0.31 & \\
\hline Standard deviation & 0.11 & 0.08 & 0.08 & 0.09 & \\
\hline Minimum & 0.19 & 0.26 & 0.19 & 0.19 & \\
\hline Maximum & 0.56 & 0.47 & 0.46 & 0.56 & \\
\hline \multicolumn{6}{|l|}{ ТТОT (s) } \\
\hline Mean & 0.95 & 1.01 & 0.86 & 0.94 & 0.47 \\
\hline Median & 0.98 & 1.02 & 0.82 & 0.90 & \\
\hline Standard deviation & 0.21 & 0.27 & 0.18 & 0.22 & \\
\hline Minimum & 0.65 & 0.65 & 0.64 & 0.64 & \\
\hline Maximum & 1.27 & 1.45 & 1.17 & 1.45 & \\
\hline \multicolumn{6}{|l|}{$V_{T} / T_{1}$} \\
\hline Mean & 4.18 & 4.62 & 5.34 & 4.72 & 0.32 \\
\hline Median & 3.88 & 5.12 & 5.40 & 4.75 & \\
\hline Standard deviation & 1.81 & 1.40 & 1.27 & 1.53 & \\
\hline Minimum & 2.24 & 2.99 & 3.59 & 2.24 & \\
\hline Maximum & 8.16 & 6.69 & 7.47 & 8.16 & \\
\hline \multicolumn{6}{|l|}{ Т//ТTот } \\
\hline Mean & 0.37 & 0.32 & 0.36 & 0.35 & 0.36 \\
\hline Median & 0.37 & 0.32 & 0.38 & 0.35 & \\
\hline Standard deviation & 0.07 & 0.04 & 0.05 & 0.06 & \\
\hline Minimum & 0.27 & 0.26 & 0.27 & 0.26 & \\
\hline Maximum & 0.45 & 0.39 & 0.42 & 0.42 & \\
\hline
\end{tabular}

\section{Results}

The results (mean, median, standard deviation, minimum and maximum values) of respiratory cycle-related parameters $\left(\mathrm{V}_{\mathrm{T}}, \mathrm{T}_{\mathrm{I}}\right.$, $\mathrm{T}_{\mathrm{TOT}}, \mathrm{V}_{\mathrm{T}} / \mathrm{T}_{\mathrm{I}}$ and $\mathrm{T}_{\mathrm{I}} / \mathrm{T}_{\mathrm{TOT}}$ ), as well as the corresponding $\mathrm{P}$ values of ANOVA are presented in Table 2. No significant differences were observed among the three groups for any of the cycle-related parameters. When the functional parameters $\left(\mathrm{E}_{\mathrm{L}}, \mathrm{R}_{\mathrm{L}}, \mathrm{FRC} / \mathrm{kg}\right)$ and Lm were analyzed, no significant differences were observed among the 3 groups, except for FRC/kg $(\mathrm{P}=0.03)$ (Table 3). When the Student-Newman-Keuls multiple comparison test was employed, s-45 and s90 animals were similar with respect to FRC/ $\mathrm{kg}$ but both groups presented higher means than the control group $(\mathrm{P}<0.05)$. Figure 2 presents the box-plots for the functional parameters and Lm for all groups.

When the two groups of smoking rats were pooled into a single group (s-45 + s-90) and compared to controls by the Student $t$ test, respiratory cycle-related parameters did not differ significantly between groups. Smoking animals exhibited significantly lower values of lung elastance $(\mathrm{P}=0.046)$, and higher values of $\mathrm{FRC} / \mathrm{kg}(\mathrm{P}=0.006)$ and $\mathrm{Lm}(\mathrm{P}=0.025)$ than controls.

Table 4 shows the results of the pathological scoring of the airways (inflammation, secretory hyperplasia, muscular hypertrophy and fibrosis) at both the axial and lateral bronchus levels. When the three groups were compared individually by the KruskalWallis test, inflammation and muscular hypertrophy at the axial level exhibited significant differences among groups $(\mathrm{P}=0.033$ and $\mathrm{P}=0.001$, respectively). After the multiple pairwise testing procedure was applied, the s-90 animals presented higher values of these parameters than controls $(\mathrm{P}<0.05)$. However, when the smoking groups were pooled and the Mann-Whitney test was applied, smoking rats presented significantly higher values of inflammation in both the 
axial $(\mathrm{P}=0.043)$ and lateral $(\mathrm{P}=0.028)$ bronchi, and higher values of airway secretory hyperplasia $(\mathrm{P}=0.024)$ and smooth muscle hypertrophy $(\mathrm{P}=0.005)$ at the level of the axial bronchus than controls. No other differences were observed.

\section{Discussion}

Epidemiological evidence has disclosed a striking association between tobacco consumption and pulmonary emphysema in humans. Interestingly, there are only few animal models of emphysema due to tobacco smoke inhalation. Experimental emphysema has been mostly induced by intratracheal instillation of proteolytic enzymes (11). Enzymatic treatments are able to induce significant airspace enlargement, but do not accurately reproduce the mechanisms of alveolar destruction consequent to chronic tobacco inhalation observed in man. Elastase instillation is one of the models most extensively used to produce emphysema in rodents (11). Animals submitted to elastase treatment develop an acute inflammation of the alveolar territory characterized by hemorrhage followed by a period of organization of intraalveolar exudate, lasting 3 to 4 weeks (11). In contrast, pulmonary emphysema in hu-

Figure 2 - Box-plots for the functional parameters $\left(E_{L}=\right.$ pulmonary elastance; $R_{L}=$ pulmonary resistance; $F R C /$ $\mathrm{kg}=$ functional residual capacity corrected for body weight) and mean linear intercept $(\mathrm{Lm})$ for controls $(\mathrm{N}=$ 8), and rats exposed to cigarette smoke for 45 (s-45; N $=7$ ) or 90 days (s-90; $N=8)$. *Values more than 3 boxlengths from the upper (75th percentile) or lower (25th percentile) edge of the box (ANOVA). +Values more than 1.5 box-lengths from the upper (75th percentile) or lower (25th percentile) edge of the box (ANOVA).
Table 3 - Effect of passive smoking for 45 and 90 days on functional respiratory parameters.

$\mathrm{E}_{\mathrm{L}}=$ Pulmonary elastance; $\mathrm{R} \mathrm{L}=$ pulmonary resistance; $\mathrm{FRC} / \mathrm{kg}=$ functional residual capacity corrected for body weight; $L m=$ mean linear intercept. The $P$ value for the comparison of the three groups by ANOVA is given in the last column.

\begin{tabular}{|c|c|c|c|c|c|}
\hline & \multicolumn{3}{|c|}{ Group } & \multirow{2}{*}{$\begin{array}{l}\text { Group } \\
\text { (total) }\end{array}$} & \multirow{2}{*}{$\begin{array}{l}\text { ANOVA } \\
\text { ( } P \text { value) }\end{array}$} \\
\hline & $\begin{array}{l}\text { Control } \\
(\mathrm{N}=8)\end{array}$ & $\begin{array}{c}s-45 \\
(N=7)\end{array}$ & $\begin{array}{c}s-90 \\
(N=8)\end{array}$ & & \\
\hline \multicolumn{6}{|l|}{$\mathrm{E}_{\mathrm{L}}\left(\mathrm{cmH}_{2} \mathrm{O} / \mathrm{ml}\right)$} \\
\hline Mean & 2.19 & 1.70 & 1.50 & 1.80 & 0.12 \\
\hline Median & 2.11 & 1.82 & 1.47 & 1.84 & \\
\hline Standard deviation & 0.59 & 0.65 & 0.72 & 0.69 & \\
\hline Minimum & 1.39 & 0.80 & 0.43 & 0.43 & \\
\hline Maximum & 3.07 & 2.42 & 2.61 & 3.07 & \\
\hline \multicolumn{6}{|l|}{$\mathrm{R}_{\mathrm{L}}\left(\left(\mathrm{cmH} \mathrm{C}_{2} \mathrm{O} / \mathrm{ml}\right) / \mathrm{s}\right)$} \\
\hline Mean & 0.27 & 0.32 & 0.30 & 0.29 & 0.47 \\
\hline Median & 0.26 & 0.31 & 0.28 & 0.27 & \\
\hline Standard deviation & 0.06 & 0.08 & 0.10 & 0.08 & \\
\hline Minimum & 0.19 & 0.23 & 0.13 & 0.13 & \\
\hline Maximum & 0.41 & 0.44 & 0.46 & 0.46 & \\
\hline \multicolumn{6}{|l|}{$\mathrm{FRC} / \mathrm{kg}(\mathrm{ml} / \mathrm{kg})$} \\
\hline Mean & 3.78 & 6.33 & 6.46 & 5.49 & 0.03 \\
\hline Median & 3.67 & 7.36 & 6.62 & 5.89 & \\
\hline Standard deviation & 1.75 & 2.63 & 1.63 & 2.31 & \\
\hline Minimum & 1.97 & 1.87 & 4.01 & 1.87 & \\
\hline Maximum & 6.90 & 9.23 & 9.05 & 9.23 & \\
\hline \multicolumn{6}{|l|}{$\operatorname{Lm}(\mu \mathrm{m})$} \\
\hline Mean & 66.44 & 87.65 & 82.63 & 78.53 & 0.25 \\
\hline Median & 62.30 & 91.44 & 76.96 & 71.97 & \\
\hline Standard deviation & 11.89 & 23.79 & 17.02 & 19.42 & \\
\hline Minimum & 51.46 & 60.27 & 67.75 & 51.46 & \\
\hline Maximum & 84.43 & 117.53 & 110.26 & 117.53 & \\
\hline
\end{tabular}
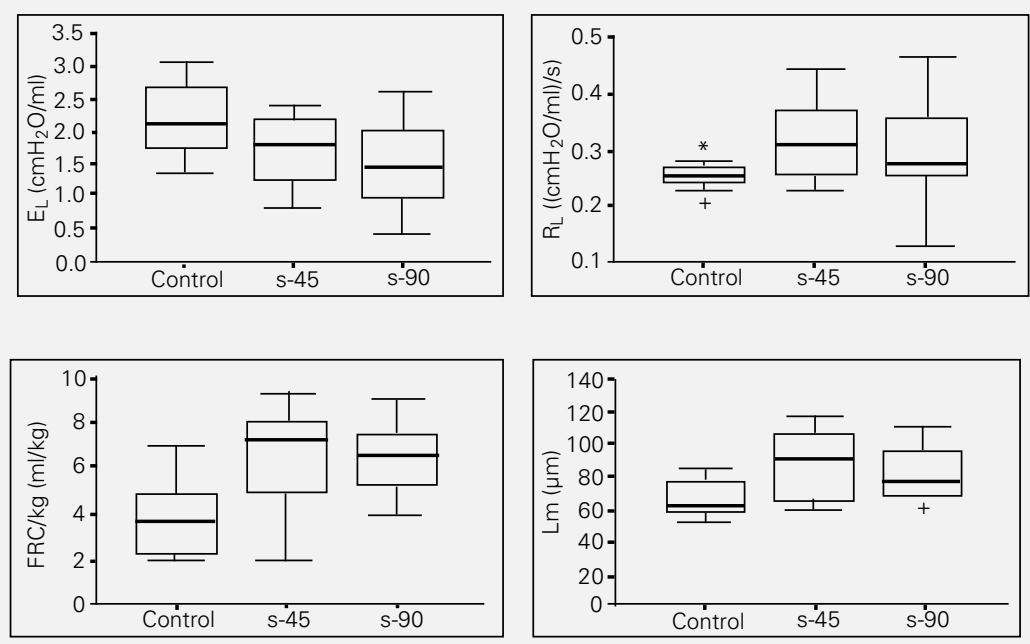
mans is a chronic disease that develops only after years of tobacco consumption. The differences in the time course of alveolar destruction observed between the protease instillation methods and the process occurring in human smokers indicate that inhalation models of tobacco-induced emphysema are necessary to study the natural history of pulmonary emphysema.

Chronic inhalation studies are usually costly and time consuming. Thus, it would be of great interest to develop short-term experimental models of tobacco-induced emphysema, especially if small animals are

Table 4 - Effect of passive smoking on the pathological score of airways at the axial (A) and lateral (L) levels.

(a) P values for comparison of the three groups (Kruskal-Wallis); (b) Since none of the animals presented secretory hyperplasia in the lateral airways, the statistical test was not performed.

\begin{tabular}{|c|c|c|c|c|c|c|c|c|c|}
\hline \multirow[t]{2}{*}{ Group } & \multirow[t]{2}{*}{ Rat } & \multicolumn{2}{|c|}{ Inflammation } & \multicolumn{2}{|c|}{$\begin{array}{c}\text { Secretory } \\
\text { hyperplasia }\end{array}$} & \multicolumn{2}{|c|}{$\begin{array}{c}\text { Muscular } \\
\text { hypertrophy }\end{array}$} & \multicolumn{2}{|c|}{ Fibrosis } \\
\hline & & A & L & A & $\mathrm{L}$ & A & L & A & $\mathrm{L}$ \\
\hline \multirow[t]{8}{*}{ Control } & 1 & 0 & 0 & 0 & 0 & 0 & 0 & 0 & 0 \\
\hline & 2 & 1 & 0 & 0 & 0 & 0 & 0 & 0 & 0 \\
\hline & 3 & 3 & 0 & 1 & 0 & 1 & 0 & 0 & 0 \\
\hline & 4 & 0 & 0 & 0 & 0 & 0 & 0 & 0 & 0 \\
\hline & 5 & 0 & 0 & 0 & 0 & 0 & 0 & 0 & 0 \\
\hline & 6 & 1 & 0 & 1 & 0 & 0 & 0 & 0 & 0 \\
\hline & 7 & 2 & 0 & 1 & 0 & 0 & 0 & 0 & 0 \\
\hline & 8 & 1 & 0 & 0 & 0 & 0 & 0 & 0 & 0 \\
\hline \multirow[t]{7}{*}{$s-45$} & 1 & 0 & 0 & 0 & 0 & 0 & 0 & 0 & 0 \\
\hline & 2 & 1 & 1 & 1 & 0 & 0 & 0 & 0 & 0 \\
\hline & 3 & 2 & 1 & 1 & 0 & 1 & 0 & 0 & 0 \\
\hline & 4 & 1 & 1 & 1 & 0 & 1 & 0 & 0 & 0 \\
\hline & 5 & 2 & 0 & 3 & 0 & 1 & 0 & 0 & 0 \\
\hline & 6 & 1 & 0 & 1 & 0 & 0 & 0 & 0 & 0 \\
\hline & 7 & 3 & 0 & 2 & 0 & 1 & 1 & 0 & 0 \\
\hline \multirow[t]{8}{*}{ s-90 } & 1 & 2 & 0 & 3 & 0 & 1 & 0 & 0 & 0 \\
\hline & 2 & 2 & 0 & 0 & 0 & 1 & 0 & 0 & 0 \\
\hline & 3 & 2 & 0 & 1 & 0 & 1 & 0 & 0 & 0 \\
\hline & 4 & 2 & 0 & 1 & 0 & 2 & 1 & 0 & 0 \\
\hline & 5 & 3 & 0 & 1 & 0 & 2 & 0 & 0 & 0 \\
\hline & 6 & 2 & 0 & 0 & 0 & 1 & 0 & 0 & 0 \\
\hline & 7 & 3 & 2 & 2 & 0 & 3 & 2 & 3 & 1 \\
\hline & 8 & 2 & 1 & 2 & 0 & 1 & 0 & 0 & 0 \\
\hline $\begin{array}{l}\text { Kruskal-Wallis } \\
\text { (P value) (a) }\end{array}$ & & 0.033 & 0.161 & 0.074 & (b) & 0.001 & 0.334 & 0.392 & 0.392 \\
\hline
\end{tabular}

employed. Such an approach is of interest for toxicological studies since it opens the possibility of using isogenic animals and also permits the use of genetic manipulations for the study of tobacco-related lung diseases. Moreover, the use of small animals obviously leads to a significant reduction in experimental costs. In an elegant study, Wright and Churg (5) recently reported that guinea pigs develop progressive lung destruction characterized by both functional and morphological parameters after 90 days of continuous tobacco exposure. Our objective was to develop a method for inducing emphysema in rats within a shorter time by increasing the amount of tobacco smoke to which the rats are exposed.

In the present study, distal airspace destruction was observed after 45 days of passive smoking. In addition, smoking rats showed an increased FRC/kg and a decreased elastic recoil of the lung (Figure 2). These findings mimic some of the most characteristic aspects of emphysema in humans. In addition, the model of passive smoking employed in this study is quite simple and inexpensive, in contrast to the conventional smoking devices (4).

The concentration of tobacco smoke used in the present study was able to induce emphysema within a short period, but was low enough to keep the animals alive for 90 days. We did not lose any animal during the experimental exposure period, and studies underway in our laboratory using larger series of animals have demonstrated that this level of intoxication is safe and avoids significant animal losses.

One important observation is that the morphological aspect of the emphysema of our rats was not the same as that usually seen in humans. The emphysematous lesions observed in our animals were widely distributed within the pulmonary parenchyma, with a slight predominance in the subpleural regions, in contrast to the marked centrilobular distribution of human emphysema. This find- 
ing may be due to anatomical differences between species. Rats have a predominantly monopodial airway branching pattern, with a small number of airway generations before reaching the air exchanging territories, whereas humans exhibit a dichotomous branching pattern with about 16 generations proximal to terminal bronchioles (12).

Interestingly, the severity of functional impairment did not progress with an additional 45-day exposure, since s-45 and s-90 rats presented similar values of $\mathrm{E}_{\mathrm{L}}, \mathrm{FRC} / \mathrm{kg}$ and $\mathrm{Lm}$ (Figure 2). Since lesions due to tobacco smoke are time-dependent (5), it is possible that more subtle alterations could be detected within a period of time shorter than 45 days under the present experimental conditions.

The airways of tobacco-exposed rats also developed histopathological changes compatible with chronic irritation. The inflam- matory score and the amount of airway smooth muscle increased with time, and tended to be more severe in s-90 animals (Table 4).

In conclusion, we have described a method for inducing experimental emphysema in rats by chronic tobacco smoke inhalation in which significant functional alterations were detected after 45 days of exposure. The time needed to obtain emphysematous lesions due to tobacco inhalation was close to the time range described for the conventional models of intratracheal enzymatic instillation. The concentration of tobacco smoke employed was safe enough to avoid significant animal deaths during the experiment. Due to its simplicity, low cost and short duration, this technique may be a useful model to obtain new information about airspace remodeling due to chronic tobacco consumption.

\section{References}

1. Park SS, Kikawa Y, Goldring IP, Daly MM, Zelefsky M, Shim C, Spierer M \& Morita T (1977). An animal model of cigarette smoking in beagle dogs. American Review of Respiratory Disease, 115: 971 979.

2. Zwicker GM, Filipy RE, Park JF, Loscutoff SM, Raga HA \& Stevens DL (1978). Clinical and pathological effects of cigarette smoke exposure in beagle dogs. Archives of Pathology and Laboratory Medicine, 102: 623-628.

3. Heckman CA \& Dalbey WE (1982). Pathogenesis of lesions induced in rat lung by chronic tobacco smoke inhalation. Journal of the National Cancer Institute, 69: 117-129.

4. Huber GL, Davies P, Zwilling GR, Pochay VE, Hinds WC, Nicholas HA, Mahajan VK, Hayashi M \& First MW (1981). A morphologic and physiologic bioassay for quantifying alterations in the lung following experimental chronic inhalation of tobacco smoke. Bulletin Européen de Physiopathologie Respiratoire, 17: 269-327.
5. Wright JL \& Churg A (1990). Cigarette smoke causes physiologic and morphological changes of emphysema in the guinea pig. American Review of Respiratory Disease, 142: 1422-1428.

6. Le Mesurier SM, Stewart BW \& Likke AWJ (1981). Injury to type-2 pneumocytes in rats exposed to cigarette smoke. Environmental Research, 24: 207-217.

7. Cardoso WV, Saldiva PHN, Criado PMP, Sakae RS, Zin WA \& Böhm GM (1991). A comparison between the isovolume and the end-inflation occlusion methods for measurement of lung mechanics in rats. Journal of Applied Toxicology, 11: 79-84.

8. Mortola JP \& Noworaj A (1983). Two-sidearm tracheal cannula for respiratory airflow measurements in small animals. Journal of Applied Physiology, 55: 250253.
9. Zin WA, Martins MA, Silva PRM, Sakae RS, Carvalho ALI \& Saldiva PHN (1989). Effects of abdominal opening on respiratory system mechanics in ventilated rats. Journal of Applied Physiology, 66: 24962501.

10. Thurlbeck WM (1967). Internal surface area and other measurements in emphysema. Thorax, 22: 483-496.

11. Snider GL, Lucey EC \& Stone PJ (1986). Animal models of emphysema. American Review of Respiratory Disease, 133: 149169.

12. Yeh HC, Schum GM \& Duggan MT (1979) Anatomic models of the tracheobronchial and pulmonary regions of the rat. Anatomical Record, 195: 483-492. 